\title{
Research and Application of Pollution Control in the Middle Reach of Ashe River by Multi-Objective Optimization
}

\author{
Yuanyuan Wang ${ }^{1}$, Liang Guo ${ }^{1,2}$, Yi Wang ${ }^{1}$, Meng Ran ${ }^{1}$, Jie Liu ${ }^{1}$, Peng Wang ${ }^{1,2 *}$ \\ ${ }^{1}$ School of Municipal and Environmental Engineering, Harbin Institute of Technology, Harbin, China \\ ${ }^{2}$ State Key Laboratory of Urban Water Resource and Environment, \\ Harbin Institute of Technology, Harbin, China \\ Email: pwang73@vip.sina.com
}

Received July 2013

\begin{abstract}
Based on one-dimensional water quality model and nonlinear programming, the point source pollution reduction model with multi-objective optimization has been established. To achieve cost effective and best water quality, for us to optimize the process, we set pollutant concentration and total amount control as constraints and put forward the optimal pollution reduction control strategy by simulating and optimizing water quality monitoring data from the target section. Integrated with scenario analysis, COD and ammonia nitrogen pollution optimization was studied in objective function area from Mountain Maan of Acheng to Fuerjia Bridge along Ashe River. The results showed that COD and NH3-N contribution has been greatly reduced to Ashe River by $49.6 \%$ and $32.7 \%$ respectively. Therefore, multi-objective optimization by nonlinear programming for water pollution control can make source sewage optimization fairly and reasonably, and the optimal strategies of pollution emission are presented.
\end{abstract}

Keywords: One-Dimensional Water Quality Model; Point Source Pollution Reduction; Multi-Objective Optimization; Middle reach of Ashe River

\section{Introduction}

With the rapid development of China's economy and the speeding up of urbanization, water pollution and shortage of water resources have become very serious, so water pollution management is imperative. However, in our country, river basin pollution control is incompatible with social economic development, and economic decisions often run counter to the environment (http://wfs.mep.gov.cn/zdlyshew/), so the protection of the water environment should be in the social, economic and environmental system. Water pollution control is a multi-objective optimization problem, which can make the river water quality standard and pollution control cost effective without affecting the premise of social and economic development. According to the types of pollution source, the discharge of pollutants and emissions have great difference, sewage treatment fee is difficult to quantify, so from the perspective of the water environmental capacity control (Qian et al., 2008), and the river water quality reaching the water requirements under the premise of function planning, we carried out water pollution reduction control of pollution points sources in the river, considering minimizing the sum of squares routine index of rate as economic target. We study the middle heavy pollution reduction zone of Ashe River basin as an example, consider the coupling comprehensive multi-objective linear programming and genetic algorithm with global optimization characteristics (S.A.B. et al., 2007; Sun et al., 2007; R.Z. et al., 2007), combined with a one dimensional water quality model, and use the theory of scenario analysis to make strong concentration control of the pollution source, and provide technical support for river basin water pollution control.

\section{Methods}

\section{Study Area}

Ashe River(Li et al., 2007; Li et al., 2011) locates in Heilongjiang Province, as an important tributary of the right bank of the Songhua River, which originates in MaoEr hills of ShangZhiShi, and flows through ShangZhiShi, following by Harbin city, XiangFangOu, DaoWaiOu, finally into the Songhua River. Ashe River, known as "Gold River", has received a large number of industrial wastewater and sewage in the rapid development of local economy and the water ecological environment of river has been completely damaged, which posed a serious threat to water quality of Songhua River. Ashe River belongs to the mountain river, whose water supply is given priority to atmospheric rainfall that mainly concentrated in 6 9 month, and accounted for about $70 \% \sim 80 \%$ of the total annual precipitation, besides river frozen winter period generally lasts more than four months. There are two environment function areas in Ashe River, respectively maanshan station-Ashe River and west spring reservoir-ma a shan station. We mainly focus on maanshan station-tuerjia bridge function area covering Acheng qu as the study area, with total length of $113 \mathrm{~km}$, whose direct pollution sources are Yeast enterprise, pharmaceutical company, sewage plant and so on. There are many tributaries in the middle of Ashe River, such as Yuquan River, Nandagou, Chengnangou, Haigou River and Miaotaizigou. All of them received sewage and industrial waste water from city. So, we should view these tributaries as pollution outlet in order to carry on pollution control strategy research.

Yuquan river's sewage and wastewater mainly comes from the yuquan street residents' domestic wastewater, some small 
factory's waste water, and coastal agricultural non-point wastewater; Nandagou and Chengnangou, originally small seasonal rivers, mostly received through storm water from double fung street and Acheng City; A pharmaceutical company, a yeast and a sewage plant's pollution concentration and the mass is constant throughout the year; Haigou River and Miaotaizigou are seasonal rivers, which received the sewage flowing through the town. The dynamic emission mass of corresponding index of every pollution outlets can be obtained by multiplying the concentration $(\mathrm{mg} / \mathrm{L})$ and emissions $\left(\mathrm{m}^{3} / \mathrm{s}\right)$ with conversing the unit. Based on villages and towns sewage discharge of pollutants characteristics, we choose $\mathrm{COD}$ and $\mathrm{NH}_{3}-\mathrm{N}$ as main pollution index to have water environment quality research, as shown in Figure 1.

\section{The Establishment of Pollution Reduction Based on Multi-Objective Linear Optimization Model}

Water environmental planning involves the ecological, environmental, economic, technical and social life, whose main goal is to achieve the water quality standard and make wastewater treatment cost the lowest (Huang et al., 2008; Lin et al., 2006). After pollutants flow into the river, there are three movement forms, for example, migration by environmental medium, con- taminant particle dispersion, and pollutants transformation and attenuation. Therefore, we think that pollutants from sewage plants have fully combined with vertical and horizontal process of the river. Then, we simulate river pollution sources by onedimensional water quality model, which can make pollution emission wonderfully linked with water environmental capacity of functions, so as to improve the operability of pollution reduction optimization.

The model is composed of objective function and constraints conditions. Firstly, we should set corresponding reduction rate $\lambda_{k}\left(0<\lambda_{k}<1\right)$ to $k$ pollution sources intensities, that means it can be become $Q_{k}\left(1-\lambda_{k}\right)$ after reduction. Constraint conditions are that pollutants from every pollution outlets combined well with river should be achieved with water index standards (Tian et al., 2010). So, the model is shown as the following:

$$
\begin{aligned}
& \min T_{k(1)}=\sum_{k=1}^{m} Q_{k(1)} u_{k(1)} \lambda_{k(1)} \\
& \min T_{k(2)}=\sum_{k=1}^{m} Q_{k(2)} u_{k(2)} \lambda_{k(2)} \\
& \min T_{k(n)}=\sum_{k=1}^{m} Q_{k(n)} u_{k(n)} \lambda_{k(n)}
\end{aligned}
$$

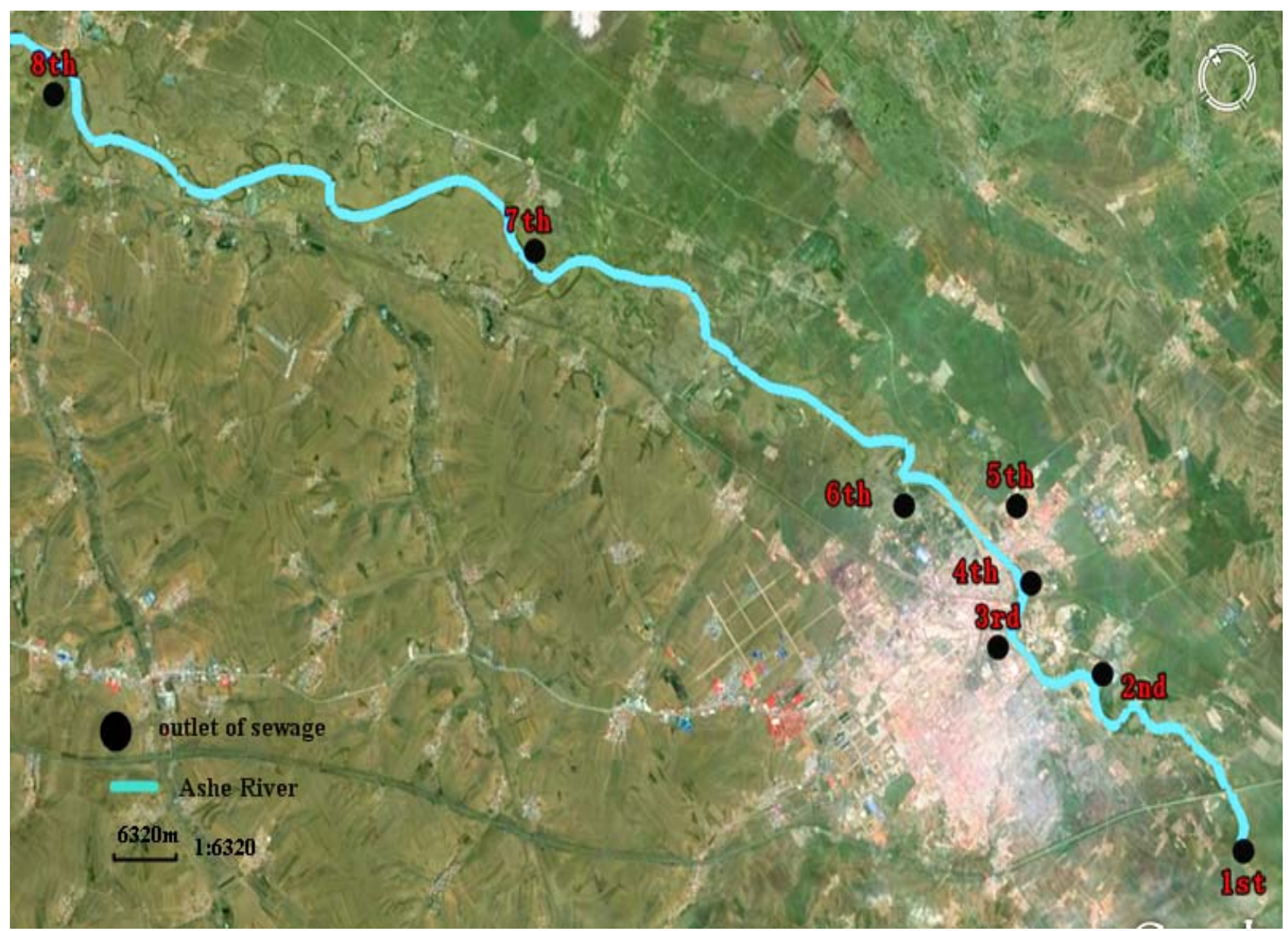

Note: 1st outlet of sewage is Yuquan River; 2nd outlet of sewage is Nandagou; 3rd outlet of sewage is Chengnangou; 4th outlet of sewage is Harbin yeast company; 5th outlet of sewage is a pharmaceutical factory; 6th outlet of sewage is a sewage treatment plant; 7th outlet of sewage is Haigoi River; 8th outlet of sewage is Miaotaizigou.

Figure 1.

The location of outlet of point source pollution. 


$$
\text { s.t. }\left\{\begin{array}{l}
C_{k(\mathrm{n})} \leq C_{s}(\mathrm{k}=1) \\
C_{k(\mathrm{n})}^{*} \leq C_{0}(\mathrm{k}=2,3,4 \ldots) \\
u_{k(\mathrm{n})}^{*}=u_{k(\mathrm{n})}\left(1-\lambda_{k(\mathrm{n})}\right) \\
C_{k(\mathrm{n})}=\frac{\Delta Q_{k} u_{k(\mathrm{n})}^{*}+\mathrm{C}_{k-1(n)}^{*} Q_{k-1}}{Q_{k-1}+\Delta Q_{k}} \\
C_{k(\mathrm{n})}^{*}=C_{k(\mathrm{n})} \exp \left(-\frac{K_{n} l_{(k-1, k)}}{86400 v}\right) \\
\mathrm{Q}_{k}=\mathrm{Q}_{0}+\sum_{i=1}^{k-1} Q_{i} \\
0 \leq \lambda_{k}(\mathrm{n})<1
\end{array}\right.
$$

Where:

$T_{k(n)}$ - the total mass needed to be managed of $n_{\mathrm{th}}$ pollution index from $k$ pollution outlets in the drain, $\mathrm{kg} / \mathrm{min}$;

$C_{k(n)}$ - the concentration of $n_{\text {th }}$ pollution index mixed well with the river when it reached $k_{\text {th }}$ pollution emission, $\mathrm{mg} / \mathrm{L}$;

$U_{k(n)}^{*}$-the concentration of $n_{\text {th }}$ pollution index of $k_{\text {th }}$ sewage plants, mg/L;

$\Delta Q_{k}$ - the total mass of $k_{\mathrm{th}}$ pollution emission, $\mathrm{m}^{3} / \mathrm{s}$;

$Q_{k}$ - the river flow mass of $k_{\text {th }}$ pollution emission after sewage water mixed in the study area, $\mathrm{m}^{3} / \mathrm{s}$;

$C_{k(n)}^{*}$-the background concentration of $n_{\mathrm{th}}$ pollution index of $k_{\text {th }}$ pollution emission, mg/L;

$K_{n}$-the degradation coefficient of $n_{\text {th }}$ pollution index, $1 / \mathrm{d}$;

$l_{(k-1, k)}$ - the distance from $(k-1)_{\text {th }}$ pollution emission to $k_{\mathrm{th}}$ pollution emission, $m$;

$\mathrm{v}$ - the mean flow rate of the study river, $\mathrm{m} / \mathrm{s}$;

$\lambda_{\mathrm{k}(\mathrm{n})}$ - the management coefficient of $n_{\mathrm{th}}$ pollution index of $k_{\mathrm{th}}$ pollution emission.

It is known that sewage treatment fee increased with the improving of emission water quality, and the water self-purification ability is linked with the economic effect of sewage treatment efficiency. Besides, it is hard to quantify, so we viewed concentration control and total amount control of pollutants as constraint condition, the minimum each pollutant reduction rate of the discharge outlet as economic target, then, we set up multi-objective optimization pollution reduction model. In the study, we choose COD and ammonia nitrogen as the overall amount control index, and obtained initial control section monitoring data of real time, $\mathrm{COD}$ and $\mathrm{NH}_{3}-\mathrm{N}$ and corresponding sources intensity index of the outlet of the emission source Q $(\mathrm{mg} / \mathrm{s})$. Finally, we can get each coefficient, which make pollution index of the outlet of every discharge achieves water quality standard.

\section{Emission Reduction and Control Optimization}

\section{Set emission Scenarios}

1) Identify pollution sources We study the decentralized points sources, including Industry pollution sources and life pollution sources in Ashe River pollution management.

2) List planning object According to the research pollution sources, we think the discharge of major pollution indicators as the pollution reduction control object, which means COD and ammonia nitrogen.

3) Build scenario In study area, Non-point source pollution refers to large area, wide range, the factors such as livestock breeding, arable land and pesticide use, compared with the point source pollution emissions small, is always negligible; Supposing that the concentration and total mass of sewage water from each emissions is constant; pollutants diffusion meets one-dimensional water quality model delete; COD concentration of Mountain Maan station-Fuerjia Bridge control section accords with IV function area standard, when $\mathrm{C}_{\mathrm{COD}}<30 \mathrm{mg} / \mathrm{L}$, $\mathrm{C}_{\mathrm{NH3}-\mathrm{N}}<1.5 \mathrm{mg} / \mathrm{L}$, there is no need to be reduced, however, when $\mathrm{C}_{\mathrm{COD}}>30 \mathrm{mg} / \mathrm{L}, \mathrm{C}_{\mathrm{NH} 3-\mathrm{N}}>1.5 \mathrm{mg} / \mathrm{L}$ (Zhao et al., 2010), it will be necessary to have optimal reduction by multi-objective optimization model.

\section{Pollution Reduction Control Technology Framework in River}

The calculating methods and implementation process of multi-objective planning pollution reduction model in view of decentralized point sources are as follows:

1) Determine the study area, make a survey about the river blow-down circumstance through the local environmental monitoring station, and identify the characteristics pollutants needed to be controlled and its concentration.

2) According to basin hydraulic conditions and mixing-diluted-diffusion characteristics of characteristic pollutants in water body, select the appropriate model to simulate the pollutants concentration change after flowing into the river, and set up multi-objective optimization pollution reduction model associated with the function of water environment capacity in order to minimize pollution in rivers.

3) Set the reduction rate with random value in initial of the outlet, and obtain minimum rate combination that could satisfy the requirement of water quality in water function area by multi-objective optimization.

4) Continue to search and do overalls of optimization, until the optimal combination of cutting rate conforming to the conditions, then the result could be output, according to the results, put forward corresponding water environmental management strategy (http://datacenter.mep.gov.cn/trs/query.action).

\section{Model Application}

\section{Regional Drainage Analysis}

In this paper, water quality management was carried out in the middle heavy pollution reduction zone of Ashe River by using the multi-objective planning model, and proposed pollution prevention and control countermeasures according to the results of the simulation. There are eight main outlets in the Acheng section of Ashe River, and we can set up efficient economic sewage treatment facilities with high efficiency to improve water quality through the reduction rate of each outlet whose main pollution indicators are $\mathrm{COD}$ and $\mathrm{NH}_{3}-\mathrm{N}$. We found that the total annual COD contribution from eight main outlets to Ashe River is $13332.83 \mathrm{t} / \mathrm{a}$, the NH3-N is $433.13 \mathrm{t} / \mathrm{a}$, and the total amount contribution of 6th sewage plant is $1825 \mathrm{~m}^{3} / \mathrm{a}$; from Table 1, the 2nd drain outlet to Ashe River has the maximum contribution of COD each year, accounting for about $40 \%$; the 6 th has a large amount of ammonia nitrogen pollution contribution to Ashe River, whose ammonia nitrogen contribution to Ashe River accounts for more than 33\% of all outlet. Finally, pollution contribution of COD and ammonia nitrogen emissions from various sources to Ashe River are shown in Table 1. 


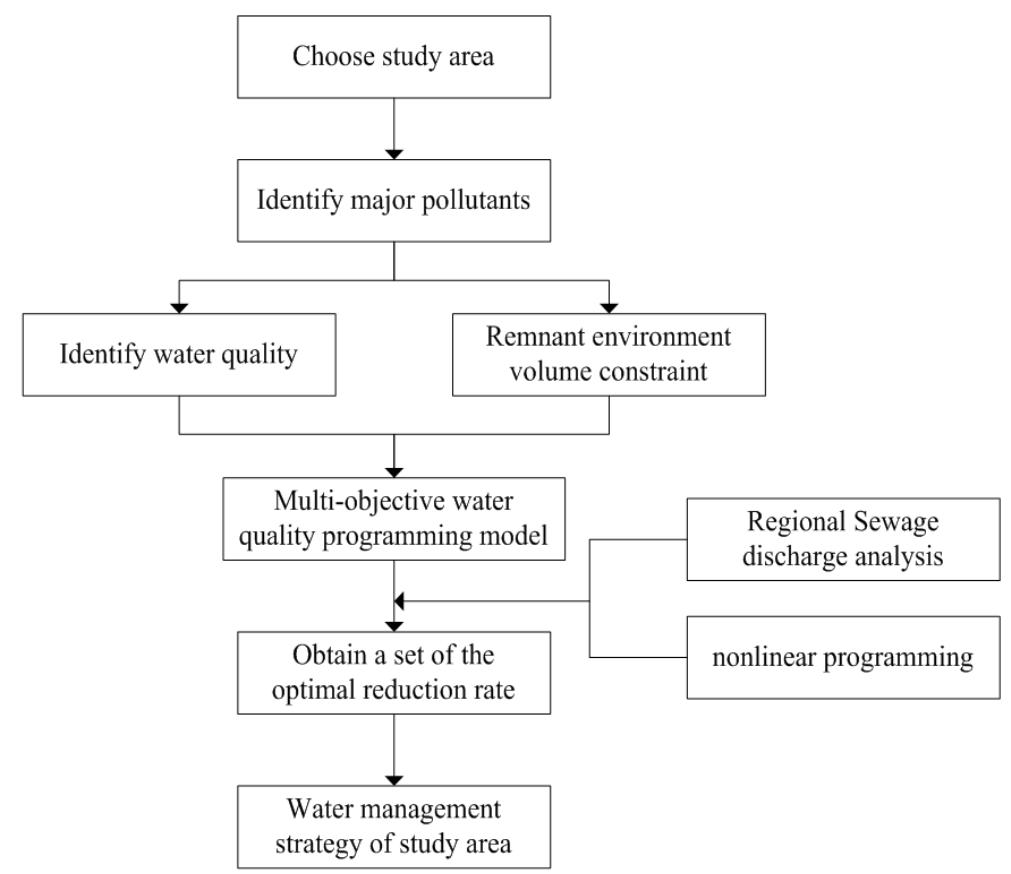

Figure 2.

The calculating methods and implementation process of using multi-objective planning pollution reduction model.

Table 1.

Emission of water pollutants from every pollution source of Ashe River in 2012.

\begin{tabular}{cccc}
\hline \multirow{2}{*}{ Pollution Sources } & \multirow{2}{*}{ Sewage Discharge Volume (million m $\left.{ }^{3} / \mathrm{a}\right)$} & \multicolumn{2}{c}{ Emission of Water Pollutants of Ashe River (t/a) } \\
\cline { 3 - 4 } 1st & 890 & $\mathrm{COD}$ & $\mathrm{NH}_{3}-\mathrm{N}^{2}$ \\
2nd & 650 & 1335 & 76.60 \\
3rd & 460 & 5453.5 & 22.56 \\
4th & 35.3 & 1573.2 & 75.44 \\
5th & 38.64 & 92.48 & 6.35 \\
6th & 1825 & 32.92 & 1.06 \\
7th & 1200 & 1095 & 146 \\
8th & 1600 & 1440.73 & 55.36 \\
Total & 6698.94 & 2310 & 59.76 \\
\hline
\end{tabular}

\section{Case Analysis}

The eight outlet information of Mountain Mana station-Fuerjia Bridge monitoring section in the middle reaches of Ashe River has been described in Section 1.1. Now, we simplified the pollution discharge process, as shown in Figure 3. According to the available Harbin environmental monitoring central station monitoring data in 2012, we got that the COD concentration of the upstream water outlet of the $1 \mathrm{st}\left(\mathrm{C}_{\mathrm{COD}}\right)$ is 12.5 $\mathrm{mg} / \mathrm{L}$, ammonia nitrogen concentration $\left(\mathrm{C}_{\mathrm{NH} 3-\mathrm{N})}\right.$ is $.20 \mathrm{mg} / \mathrm{L}$. Considering water function zone, the water quality of Acheng section in Ashe River needs to meet water quality standards of GB3838-2002 class IV, so, we set $\mathrm{C}_{\mathrm{COD}}$ with $30 \mathrm{mg} / \mathrm{L}$ and $\mathrm{C}_{\mathrm{NH} 3 \mathrm{~N}}$ with $.15 \mathrm{mg} / \mathrm{L}$ in the model. In the analysis, we firstly choose the Mountain Maan station monitoring average flow rate for many years as the middle-up flow parameters in emission reduction model, according to Ashe River years monitoring data combined with local actual situation. Then, according to related data of water environmental quality status in the Ashe River middle reaches, we calculate and determine that selfpurification coefficient of COD emissions from various sources is .1, and ammonia nitrogen's self-purification coefficient is .06.

Based on monitoring data, we established the multi-objective programming function viewing the minimal total mass of pollutants index reduction as the objective and the function is as the following:

$$
\begin{aligned}
& \min T_{\text {COD }} \\
= & 2.5 \lambda_{1}+10.4 \lambda_{2}+3 \lambda_{3}+0.2 \lambda_{4}+0.06 \lambda_{5}+2.1 \lambda_{6}+2.7 \lambda_{7}+4.4 \lambda_{8} \\
\min T_{N H_{3}-N} & \\
= & 0.14 \lambda_{1}+0.04 \lambda_{2}+0.1 \lambda_{3}+0.01 \lambda_{4}+0.002 \lambda_{5}+0.3 \lambda_{6}+0.1 \lambda_{7}+0.1 \lambda_{8}
\end{aligned}
$$

The calculating results by Matlab2011a are as the following: 


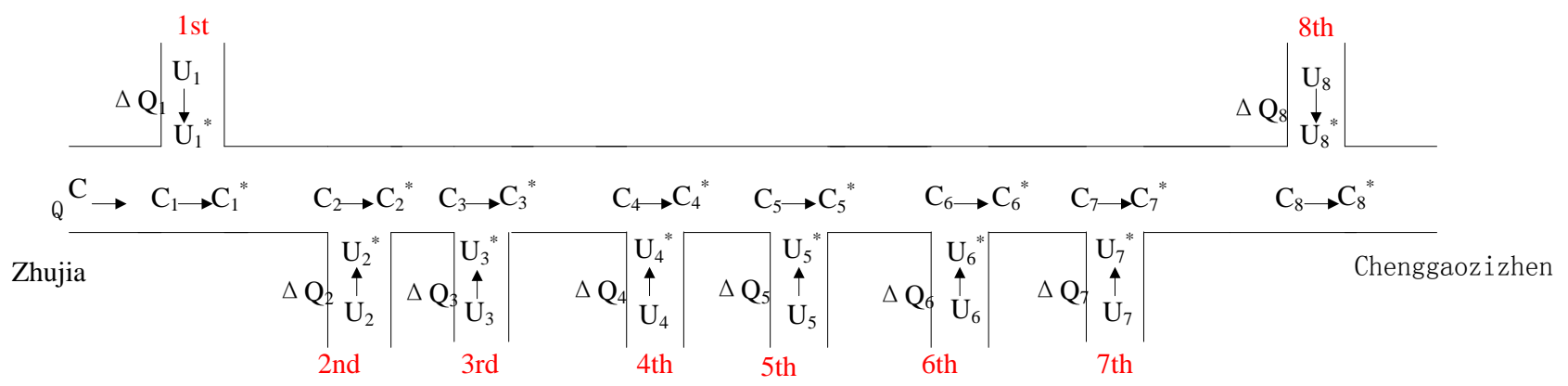

Figure 3.

Procedure of Discharge of 8 outlets around Acheng Section of Ashe River.

$\lambda_{1}=1, \lambda_{2}=.7, \lambda_{3}=1, \lambda_{4}=0, \lambda_{5}=1, \lambda_{6}=.39, \lambda_{7}=.68, \lambda_{8}=.86$. Then, we put the values of $\lambda_{1} \sim \lambda_{8}$ into multi-objective mode $\{(5)-(6)\}$ to obtain total minimum governance mass of COD and ammonia nitrogen indicators of 8 outlets: $\min T_{C O D}=$ $6620.5 \mathrm{t} / \mathrm{a}, \min T_{N H 3-N}=142.4 \mathrm{t} / \mathrm{a}$. According to the planning sewage outlets data, we obtained the $\mathrm{COD}$ and $\mathrm{NH}_{3}-\mathrm{N}$ contributions to Ashe River after corresponding reduction rates of COD and ammonia nitrogen pollution indicators, as shown in Table 2.

\section{Results and Discussion}

In the model application process, the 1st, the 3rd and the 5th sewage outlets water treatment coefficient have to be 1 , which indicates that these three sewage outlets should be improved significantly, so that $\mathrm{COD}$ and $\mathrm{NH}_{3}-\mathrm{N}$ can be achieved Grade IV water quality standard before they flew into the Ashe River. Among them, the amount of the 1st outfall and the 3rd outfall waste water are much more, which are mainly from rural enterprises (including a beer company and liquor companies), sewage and agricultural waste water, and the concentration of the main pollution indicators is bigger, so both of them need to be strengthened governance. The 5th outlet is from a pharmaceutical company, although there are relatively small discharges, the concentration of pollution indicators is greatly larger: $\mathrm{C}_{\mathrm{COD}}$ $=85.2 \mathrm{mg} / \mathrm{L}, \mathrm{C}_{\mathrm{NH} 3-\mathrm{N}}=2.73 \mathrm{mg} / \mathrm{L}$, far exceeded IV water quality standard. Besides, perennial rivers flowing through this section subjected to severely pollution, and water purification capacity is weak, so the study area needs to be emphasized for governing. In addition, the 4th outfall flow is small and sewage treatment equipment improved the enterprise itself, so the total source strength is negligible. As a result, from an economic and environmental point of view, the outfall abatement rate of 0 is deleting reasonable. Through multi-objective optimization model, each outfall COD and $\mathrm{NH}_{3}-\mathrm{N}$ indicators have been greatly reduced the contribution rate, decreased by $49.6 \%$ and $32.7 \%$. With these reduction strategies, Ashe River water quality will be greatly improved.

\section{Conclusions}

In the case of information scarcity or lack of historical data, this method can be used to simplify the water environmental system, then, we establish pollution reduction model based on multi-objective linear programming combined with one-dimensional water quality model, considering the optimal economic and optimal water quality as the goal, concentration control and total amount control as constraint conditions, to manage pollution source in the Ashe River middle reaches. In addition, we used multi-objective optimization with overall search function, and simulated or optimized the monitoring data from outlet or the target section in order to put forward the optimal control strategy to make the target functional areas standard. Compared with other single objective planning methods, this method is more flexible and practicable.

Combining with scenario analysis, we study and analyze of the $\mathrm{COD}$ and $\mathrm{NH}_{3}-\mathrm{N}$ reduction of Maanshan station-Fuerjia bridge monitoring section in the middle reaches of Ashe River was carried out, where water quality is performed class IV water quality standard. After model application, we found that $\mathrm{COD}$ and $\mathrm{NH}_{3}-\mathrm{N}$ contribution to Ashe River of each outlet has greatly reduced by $49.6 \%$ and $32.7 \%$ respectively. Therefore, the plan was realized with cost effective and environmental friendly.

Table 2.

The contribution to river and quality needs to be reduced of the key water indices.

\begin{tabular}{cccccc}
\hline $\begin{array}{c}\text { Pollution } \\
\text { Sources }\end{array}$ & $\begin{array}{c}\text { Pollution Control } \\
\text { Coefficient }\end{array}$ & $\begin{array}{c}\text { Emission Concentration } \\
\text { of COD }(\mathrm{mg} / \mathrm{L})\end{array}$ & $\begin{array}{c}\text { Emission Concentration } \\
\text { of } \mathrm{NH}_{3}-\mathrm{N}(\mathrm{mg} / \mathrm{L})\end{array}$ & $\begin{array}{c}\text { Emission of COD } \\
\text { of Ashe River }(\mathrm{t} / \mathrm{a})\end{array}$ & $\begin{array}{c}\text { Emission of } \mathrm{NH}_{3}-\mathrm{N} \\
\text { of Ashe River }(\mathrm{t} / \mathrm{a})\end{array}$ \\
\hline 1st & 1.00 & 0 & 0 & 0 & 0 \\
2nd & .7 & 25.17 & 1.04 & 5071.7 & 20.9 \\
3rd & 1.00 & 0 & 0 & 0 & 0 \\
4th & 0 & 98.3 & 12.6 & 92.48 & 6.35 \\
5th & 1.00 & 0 & 0 & 6 & 0 \\
6th & .39 & 21.41 & .66 & 465 & 89.06 \\
7th & .68 & 35.6 & .54 & 323.4 & 17.7 \\
8th & .86 & 53.9 & 1.40 & 6620.5 & 8.4 \\
Total & - & - & - & & 142.4 \\
\hline
\end{tabular}




\section{Acknowledgements}

We thank Harbin Environmental Monitoring Station for the help of the monitoring data. We acknowledge the Research Fund for "scatter point source treatment technology and demonstration of heavy pollution reduction in the middle reach of Ashe River” (2012ZX07201003-002).

\section{REFERENCES}

Chinese Ministry of Environmental Protection (2010). National "Twelve Five” plan of focus on water pollution prevention (2011-2015).

http://wfs.mep.gov.cn/zdlyshew/

Rongsun, Q. (2008). Further strengthen the control and management of water environment capacity. China Construction News.

Momtahen, S., \& Dariane, A. B. (2007). Direct search approaches using genetic algorithms for optimization of water reservoir operating policies. Journal of Water Resources Planning and Management-Asce, 133, 202-209.

http://dx.doi.org/10.1061/(ASCE)0733-9496(2007)133:3(202)

Dong, S., \& Yang, W. (2007). Genetic algorithm solution of a gray nonlinear water environment management model developed for the liming river in Daqing, China. Journal of Environmental Engineering Asce, 133, 287-293.
http://dx.doi.org/10.1061/(ASCE)0733-9372(2007)133:3(287)

Zou, R. (2007). An adaptive neural network embedded genetic algorithm approach for inverse water quality modeling. Water Resources Research. http://dx.doi.org/10.1029/2006WR005158

Hua, L. B. (2011). Water quality monitoring survey of Ashe River. Heilongjiang Science and Technology Information, 8, 81-85.

Fei, L. J., Qiang, F., \& Guo, M. Q. (2012). Basin pollution situation analysis and discussion of Ashe River. Water Conservancy Science and Technology and Economy, 3, 50-54.

Feng, H. X., Guo, S. D., \& Quan, G. W. (2008). Research of rivers emission rights allocation model by multi-objective optimization. Journal of Hydraulic Engineering, 1, 75-80.

Feng, L. G. (2006). Based on fairness, efficiency and multi-objective optimization method of river pollution load distribution. D. Thesis, Guangzhou: Zhongshan University.

Gang, T. X., Ting, J. M., \& Jian, H. (2010). Multi-objective programming model for sewage pollution control programs in the riparian Application-Minjiang River in Yibin City as an example. Resources and Environment in the Yangtze Basin, 10, 156-162.

GB3838-2002, Surface water quality standards. http://datacenter.mep.gov.cn/trs/query.action

Yi, W., Wen, L. J., \& Xue, S. (2012). Computational intelligence based optimization study on the watershed discharge of sewage. China Environmental Science, 1, 173-180. 